\title{
Ultra-processed food purchases in Norway: a quantitative study on a representative sample of food retailers
}

\author{
Siri Løvsjø Solberg*, Laura Terragni† and Sabrina lonata Granheim \\ Department of Health, Nutrition and Management, Oslo and Akershus University College of Applied Sciences, \\ Oslo, Norway
}

Submitted 13 July 2015: Final revision received 28 October 2015: Accepted 6 November 2015: First published online 23 December 2015

\begin{abstract}
Objective: To identify the use of ultra-processed foods - vectors of salt, sugar and fats - in the Norwegian diet through an assessment of food sales.

Design: Sales data from a representative sample of food retailers in Norway, collected in September 2005 ( $n$ 150) and September 2013 ( $n$ 170), were analysed. Data consisted of barcode scans of individual food item purchases, reporting type of food, price, geographical region and retail concept. Foods were categorized as minimally processed, culinary ingredients, processed products and ultra-processed. Indicators were share of purchases and share of expenditure on food categories.

Setting: Six geographical regions in Norway.

Subjects: The barcode data included 296121 observations in 2005 and 501938 observations in 2013.

Results: Ultra-processed products represented $58.8 \%$ of purchases and $48.8 \%$ of expenditure in 2013. Minimally processed foods accounted for $17.2 \%$ of purchases and $33.0 \%$ of expenditure. Every third purchase was a sweet ultra-processed product. Food sales changed marginally in favour of minimally processed foods and in disfavour of processed products between 2005 and $2013\left(\chi^{2}(3)=203195\right.$, $P<0 \cdot 001$, Cramer's $V=0 \cdot 017, P<0 \cdot 001)$.

Conclusions: Ultra-processed products accounted for the majority of food sales in Norway, indicating a high consumption of such products. This could be contributing to rising rates of overweight, obesity and non-communicable diseases in the country, as findings from other countries indicate. Policy measures should aim at decreasing consumption of ultra-processed products and facilitating access (including economic) to minimally processed foods.
\end{abstract}

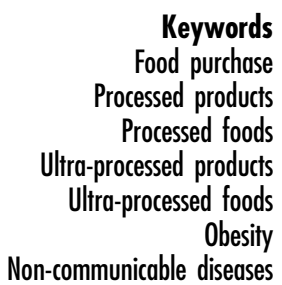

The consumption of processed foods is increasingly recognized as one of the major factors contributing to the global obesity epidemic. A new framework for classifying food based on the extent and purpose of industrial processing (Table 1) was introduced in $2009^{(1)}$ and suggests the most extensively processed products (ultra-processed products) to be the main dietary driver of the obesity epidemic.

Studies conducted with this new framework indicate that ultra-processed products are replacing traditional diets ${ }^{(2-6)}$, rapidly penetrating markets and market segments across the globe $^{(7-9)}$. Diets dominated by ultra-processed products have poor nutrient profiles ${ }^{(3,10-12)}$ and are associated with a higher prevalence of overweight, obesity ${ }^{(13,14)}$ and metabolic syndrome ${ }^{(15)}$. Other studies on processed foods indicate that they are the main vectors for sugar, salt and fats (saturated

† Correspondence address: Department of Health, Nutrition and Management, HiOA, Postboks 4, St. Olavs Plass, 0130 Oslo, Norway. and trans), directly linked with the nutrition transition and the increase in diet-related non-communicable diseases $(\mathrm{NCD})^{(16,17)}$. Consumption of ultra-processed products is also inducing unfavourable eating habits such as snacking, as they are ready-to-eat convenience foods ${ }^{(18)}$. The replacement of traditional diets for ultra-processed products has been seen as related to a food system characterized by a lightly regulated global food industry ${ }^{(7)}$. In Brazil, the new classification of food is the basis for the widely recognized food-based dietary guidelines issued in $2014^{(19)}$.

Up until now, dietary patterns based on this classification have been examined in only four countries ${ }^{(2,4,6,11)}$.

In Norway, overweight, obesity and diet-related NCD are public health issues ${ }^{(20)}$. Evidence suggests that more than half of the population is overweight, including almost $20 \%$ with obesity ${ }^{(21,22)}$. NCD account for the majority of deaths in Norway ${ }^{(22)}$. Dietary changes over the past decades have been identified as an important cause and dietary 
Table 1 The new classification of food according to the extent and purpose of industrial processing (NOVA): definitions and examples (adapted from Monteiro et al. ${ }^{(31,32)}$ )

Food group Extent of processing Characteristics

1. Unprocessed or minimally processed foods

2. Culinary ingredients

3. Processed products

4. Ultra-processed products
Extent of processing

Foods of animal or plant origin, processing does not add or introduce any substances, but may involve
subtracting parts of the food in ways that do not subtracting parts of the food in ways that do not
significantly affect its use. Processes include cleaning, peeling, portioning, skinning, boning, drying, fat reduction, pasteurization, sterilizing, chilling, freezing sealing, bottling (as such), simple wrapping, vacuum and gas packing

Processing to extract or purify constituents of foods. Specific processes include pressing, milling, crushing, grinding and pulverizing

Foods preserved in salt, sugar, brine or by smoking in order to preserve them or enhance palatability. Resulting products are often recognizable as versions of foods and are not reconstituted from them

Formulated mostly or entirely from substances derived from foods, with little or no whole food content. Often made from processed substances extracted or refined from whole foods - e.g. oils, hydrogenated oils and fats, flours and starches, variants of sugar, and cheap parts or remnants of animal foods - with little or no whole foods. In addition, so-called industrial ingredients are often used: ingredients that are not available in

supermarkets and not used in food preparation at home or in restaurants. These are of several types: further or in restaurants. These are of several types: further processed versions of culinary ingredients, such as modified starch, hydrogenated oils, high-fructose syrup, or prese
Characteristics

Foods of very different nutrient profiles, but will in appropriate combinations provide all the essential nutrients and make out the basis of healthy diets. Common features of foods in this category are the short durability and that many of them need cooking in order to be safe and edible

Nutritional properties and uses entirely different from their original foods. Most are energy-dense and nutrient-deplete, but they are typically inedible by themselves and are mostly used to enhance the flavour of meals when cooking with unprocessed and minimally processed foods

and minimally processed foods
Foods retain their basic identity, but the substances added infiltrate the foods and alter their nature. Although these products are ready to consume, they are often not consumed alone but rather as part of meals, although they may be used to replace freshly prepared dishes and meals

Products are typically not recognizable as versions of foods, although many are designed to imitate the appearance, shape or sensory qualities of food. Typically they are energy-dense, have a high glycaemic load, are low in dietary fibre, micronutrients and phytochemicals, and are high in unhealthy types of dietary fat, free sugars and sodium. Intense palatability, omnipresence and sophisticated and aggressive

marketing strategies make modest consumption of ultra-processed products unlikely and displacement of fresh or minimally processed foods very likely.

Most are designed to be consumed by themselves or in combination as snacks. These factors also make in combination as snacks. These factors also make satiety mechanisms, so promoting energy overconsumption and thus obesity
Examples

Fresh, chilled or frozen meats, fish, vegetables and fruits, milk and unflavoured yoghurt eggs, grains including flour, and water, nuts, seeds, water coffee, tea

Animal fats, oils, sugar, salt, starches

Canned, bottled, smoked meats, fish, vegetables and fruits cheese, salted nuts

Ready-to-eat/heat meals, dinner helpers, dressings, breads, reconstituted meat, fish,

vegetable products, sweets, chocolates, cakes, sweetened drinks, cheese products 
improvement is a core strategy for promoting public health by the Norwegian government ${ }^{(23)}$. Although there have been positive changes in dietary patterns over the past few years, such as increasing intakes of fish, fruits and vegetables, and decreasing intake of sugar ${ }^{(24)}$, unhealthy diets are still the largest risk factor for mortality ${ }^{(22)}$.

The present study aimed to identify the participation of ultra-processed foods (vectors of salt, sugar and fats) in the Norwegian diet through an investigation of food sales in the country, assessing: (i) current food sales and changes between 2005 and 2013 in the country as a whole; (ii) differences in food sales between six geographic regions; and (iii) differences in food sales from three retail concepts.

\section{Methods}

\section{Data source and sampling}

The data analysed in the present study are derived from monthly collection of sales data routinely carried out by Statistics Norway (SSB)* from August 2005 onwards. The data set reports from a nationally representative sample of grocery retailers and consists of barcode data generated electronically at the point of purchase for each individual sale of food and non-alcoholic beverage item. Sales for close to all food products available in Norway are reported ${ }^{(25)}$, including minimally processed foods such as fruits and vegetables. Due to extensive amounts of data reported each month, the present analysis is focused on data from September 2005 and September 2013.

The retailers were sampled, by SSB, from a population defined as grocery retailers reporting barcode data to one of the four leading retail groups in Norway ${ }^{(26)}$. The population covers more than $99 \%$ of the Norwegian grocery retail market $^{(27)}$. In the present analysis, sample size was 150 retailers in September 2005 and 170 retailers in September 2013 , accounting for about $5 \%$ of the total number of retailers in the population. The sampling procedure applied by SSB to ensure national representativeness includes stratifying retailers according to retail chains and their concepts, $\dagger$ and calculating strata size based on turnover values within each stratum. Detailed description of the sampling strategy is available elsewhere ${ }^{(25-28)}$.

\section{Data collection}

The barcode data analysed in the present study included 296121 observations (individual food item purchases) in September 2005 and 501938 observations in September 2013.

The following variables (units in brackets) were obtained for each observation from SSB: turnover (Norwegian Kroner, NOK), price (NOK per unit), county, retail concept and food

* Data are collected during the middle week of each month throughout the year for estimation of the Food Price Index, a constituent of the Norwegian Consumer Price Index.

$\dagger$ Retail chains are NorgesGruppen, Rema 1000, Coop Norge, ICA Norge and Narvesen. Concepts are supermarkets, low-price stores, convenience stores and kiosks. group (COICOP6 code). Food and beverage items are assigned by SSB to 139 food groupsł according to a UN consumption classification called COICOP (Classification of Individual Consumption According to Purpose) ${ }^{(27,29)}$. Retail chains are assigned by SSB to four retail concepts: supermarkets, low-price stores, convenience stores and kiosks. Data from the kiosk retail concept were not available for the present study, due to problems with anonymizing the data. However, these accounted for less than $1 \%$ of turnover in the sample; hence, the effect of this exclusion is minimal.

\section{Classification}

For the purposes of the present study, the barcode data were systematically analysed using a new classification system for foodstuffs developed by a Brazilian research group ${ }^{(30-32)}$, termed the NOVA classification. Food items are grouped according to the extent and purpose of industrial processing they undergo, into minimally processed foods, culinary ingredients, processed products and ultra-processed products.§ Table 1 summarizes the definitions of the food groups and provides examples of food items belonging to each group.

The 139 COICOP food groups in the barcode data were assigned to one of the food groups in the new classification. COICOP food groups that combined foods that were processed to different extents were for the most part excluded from the analysis, to avoid misclassification. These are listed in Table 2. For example, 'nuts and seeds' contains both unsalted nuts and seeds (minimally processed) and salted or roasted nuts (processed).

However, when sufficient information was available assumptions were made. For example, COICOP did not distinguish between yoghurts that are flavoured/sweetened and those that are not, thus all yoghurts were classified as ultra-processed products, as consumption of sweetened yoghurt is the most common in Norway ${ }^{(33)}$.

To assess composition of food sales within the four food groups, all observations were further divided into thirty-one subgroups (Table 3).

\section{Data analysis}

Frequency of purchase of food items (each barcode scan equals one food purchase) and expenditure on food items were used as proxies for food consumption. These indicators are not direct measures of consumption, but provide a good indication of consumption trends, as indicated in other studies $^{(17)}$.

The first analysis involved counting the share of total purchases accounted for by each of the food groups in 2005 and 2013. The relative difference in share between 2005 and

† Examples of COICOP groups are beef, poultry, salmon and trout, eggs, flours, minced meat and meatballs, cured meat, bacon, canned fish, breads, pizza, ready-to-heat dinners, dinner bases, sugar, butter, candy, baby foods and flours.

$\S$ In earlier versions of the new classification, processed and ultraprocessed products were grouped together and commonly termed 'readyto-consume products'. 
Table 2 List of excluded observations and their share of total purchases and expenditure in Norway in September 2005 and September 2013

\begin{tabular}{|c|c|c|c|c|c|}
\hline \multirow[b]{2}{*}{ Unclassified items } & \multirow[b]{2}{*}{ NOVA group } & \multicolumn{2}{|c|}{ Share of purchases (\%) } & \multicolumn{2}{|c|}{ Share of expenditure (\%) } \\
\hline & & 2005 & 2013 & 2005 & 2013 \\
\hline Pasta and noodles & 1,4 & 0.9 & 0.5 & 1.8 & 1.5 \\
\hline Some meat and poultry products* & 3,4 & 1.5 & $2 \cdot 3$ & 1.8 & 2.5 \\
\hline Pre-prepared salads & $1,3,4$ & 0.8 & 0.6 & $1 \cdot 1$ & 1.0 \\
\hline Nuts and seeds & $1,3,4$ & 1.0 & $1 \cdot 1$ & 1.0 & $1 \cdot 1$ \\
\hline Dried and processed fruits & 1,3 & 0.4 & 0.3 & 0.9 & 0.7 \\
\hline Some fish products $\dagger$ & 3,4 & 0.3 & 0.3 & 0.3 & 0.5 \\
\hline Some sweet spreads and preservesł & 2,4 & 0.1 & 0.1 & 0.2 & 0.1 \\
\hline Some milk products§ & 2,3 & 0.0 & 0.7 & 0.0 & 0.4 \\
\hline Total unclassified & - & 4.9 & 5.9 & 7.2 & 7.9 \\
\hline
\end{tabular}

*Combines cured ham and cured sausages, pâtés, side meat or knuckles, which are both processed and ultra-processed products.

†Seafood where processing is not known.

$\ddagger$ Syrup and unknown sweet spreads.

$\S$ Combines sour cream and fresh cheese.

Table 3 Share of purchases (\%) and share of expenditure (\%) in Norway in September 2005 and September 2013 for food subgroups within four food groups classified according to their extent and purpose of industrial processing, and relative change (\%)

\begin{tabular}{|c|c|c|c|c|c|c|}
\hline \multirow[b]{2}{*}{ Food group/subgroup } & \multicolumn{3}{|c|}{ Share of purchases (\%) } & \multicolumn{3}{|c|}{ Share of expenditure (\%) } \\
\hline & 2005 & 2013 & Relative change (\%) & 2005 & 2013 & Relative change $(\%)$ \\
\hline Minimally processed foods & $16 \cdot 5 \dagger$ & $17 \cdot 2^{\star}$ & $4 \cdot 2$ & $31 \cdot 8$ & 33.0 & 3.8 \\
\hline Meat and poultry & $3 \cdot 9^{*}$ & $2 \cdot 3 \dagger$ & -39.9 & 8.7 & $6 \cdot 8$ & -21.9 \\
\hline Coffee, tea & $3 \cdot 1 \dagger$ & $3 \cdot 4^{*}$ & $9 \cdot 3$ & $3 \cdot 1$ & 2.6 & $-17 \cdot 8$ \\
\hline Vegetables & $2 \cdot 2 \dagger$ & $2 \cdot 6^{*}$ & $19 \cdot 7$ & 3.9 & $5 \cdot 2$ & $35 \cdot 3$ \\
\hline Grains & $1.7 \dagger$ & $1 \cdot 8^{*}$ & $5 \cdot 3$ & 0.8 & 0.8 & 0.6 \\
\hline Fish and seafood & 1.5 & 1.5 & 0.0 & $2 \cdot 0$ & $3 \cdot 1$ & $56 \cdot 8$ \\
\hline Milk & $1.3+$ & $1.6^{*}$ & $22 \cdot 8$ & 5.4 & 4.5 & $-17 \cdot 8$ \\
\hline Water & $1.1 \dagger$ & $1 \cdot 2^{*}$ & 9.4 & 1.0 & 0.9 & $-15 \cdot 3$ \\
\hline Fruits and berries & $0.9 \dagger$ & $1 \cdot 8^{*}$ & $100 \cdot 8$ & 3.9 & $5 \cdot 8$ & 50.2 \\
\hline Roots and tubers & $0.4 \dagger$ & $0.6^{*}$ & 33.9 & 1.4 & 1.9 & 31.8 \\
\hline Eggs & 0.2 & 0.2 & $-4 \cdot 1$ & 1.5 & 1.4 & $-5 \cdot 2$ \\
\hline Culinary ingredients & 5.9 & 5.9 & 0.4 & $4 \cdot 1$ & 3.0 & $-26 \cdot 5$ \\
\hline Salt and spices & $3.6 \dagger$ & $4 \cdot 0^{*}$ & $10 \cdot 3$ & 0.9 & $1 \cdot 0$ & 8.9 \\
\hline Animal fats & $1 \cdot 1^{*}$ & $0.6 \dagger$ & -43.7 & $2 \cdot 2$ & $1 \cdot 2$ & $-48 \cdot 2$ \\
\hline Oils & $0.6 \dagger$ & $0.7^{*}$ & 12.5 & 0.3 & 0.3 & $-8 \cdot 3$ \\
\hline Sugars and sweeteners & $0.5 \dagger$ & $0 \cdot 6^{*}$ & $14 \cdot 0$ & 0.6 & 0.5 & $-8 \cdot 0$ \\
\hline Processed products & $11 \cdot 7^{\star}$ & $10 \cdot 8 \dagger$ & $-8 \cdot 2$ & $10 \cdot 8$ & 9.4 & $-13 \cdot 3$ \\
\hline Cheese & $5 \cdot 3^{*}$ & $5.0 \dagger$ & $-6 \cdot 4$ & $6 \cdot 7$ & $5 \cdot 8$ & -13.5 \\
\hline Vegetable products & 3.5 & 3.6 & $2 \cdot 0$ & 1.7 & 1.4 & $-15 \cdot 9$ \\
\hline Processed fish & $2 \cdot 5^{\star}$ & $1.8 \dagger$ & $-29 \cdot 3$ & $1 \cdot 8$ & 1.5 & -20.5 \\
\hline Processed meat and poultry & $0.4 \dagger$ & 0.5 & 9.5 & 0.6 & 0.7 & 19.5 \\
\hline Ultra-processed products & 58.7 & 58.2 & -0.8 & 48.4 & 48.8 & 0.7 \\
\hline Sweets, snacks and desserts & $18 \cdot 7^{*}$ & $16 \cdot 2 \dagger$ & $-13 \cdot 4$ & $12 \cdot 2$ & $11 \cdot 2$ & $-8 \cdot 1$ \\
\hline Cakes, pastries and cookies & $6 \cdot 4^{*}$ & $5.9 \dagger$ & -7.9 & 3.4 & 3.0 & $-11 \cdot 4$ \\
\hline Sauces and dressings & $6 \cdot 3^{*}$ & $5.8 \dagger$ & $-8 \cdot 8$ & 3.0 & $2 \cdot 1$ & -30.5 \\
\hline Breads & $4.8 \dagger$ & $6 \cdot 0^{*}$ & $26 \cdot 5$ & $6 \cdot 0$ & $7 \cdot 2$ & $19 \cdot 2$ \\
\hline Ready-to-eat/heat meals & $4.6 \dagger$ & $5 \cdot 9^{*}$ & $28 \cdot 8$ & 3.9 & 4.7 & $19 \cdot 6$ \\
\hline Ultra-processed meat and poultry & $4.5 \dagger$ & $5 \cdot 0^{*}$ & $11 \cdot 2$ & 7.4 & $7 \cdot 7$ & 4.5 \\
\hline Soft drinks & $4 \cdot 1^{*}$ & $3.5 \dagger$ & $-13 \cdot 4$ & $4 \cdot 8$ & $5 \cdot 4$ & $11 \cdot 2$ \\
\hline Squashes and juice & 2.9 & 2.9 & -0.1 & $2 \cdot 8$ & 2.4 & $-15 \cdot 0$ \\
\hline Potato chips & $1.9 \dagger$ & $2 \cdot 1^{*}$ & $7 \cdot 4$ & 1.6 & 1.9 & $19 \cdot 0$ \\
\hline Baby food products & $1.8 \dagger$ & $1.9^{*}$ & 6.9 & 0.5 & 0.5 & $-2 \cdot 4$ \\
\hline Breakfast cereals & $1.2 \dagger$ & $1.3^{*}$ & $9 \cdot 3$ & 0.6 & 0.5 & $-12 \cdot 0$ \\
\hline Margarines & $0.9^{*}$ & $0.8 \dagger$ & $-12 \cdot 3$ & 1.7 & 1.5 & $-10 \cdot 7$ \\
\hline Ultra-processed fish & $0.5 \dagger$ & $0.8^{*}$ & 58.5 & 0.5 & 0.7 & $38 \cdot 3$ \\
\hline Unclassified & $7 \cdot 2$ & 7.9 & $9 \cdot 6$ & 4.9 & 5.9 & $19 \cdot 6$ \\
\hline Grand total & $100 \cdot 0$ & $100 \cdot 0$ & 0.0 & $100 \cdot 0$ & $100 \cdot 0$ & 0.0 \\
\hline
\end{tabular}

${ }^{*}$ Count significantly higher than expected at $P<0.05$ in $X^{2}$ test.

tCount significantly lower than expected at $P<0.05$ in $X^{2}$ test.

2013 for each group was calculated and Pearson's $\chi^{2}$ tests for the association between time and food purchases were performed. The same was done for subgroups.
Second, the share of expenditure and the relative difference in share between 2005 and 2013 for the four groups and subgroups were calculated. For this indicator 
findings could not be tested for statistical significance with the data available (from only two points in time).

To assess food sales in different geographical regions, the counties were divided into six geographical regions in Norway (East, South, West, Middle, North and Oslo (capital city)). Share of purchases and expenditure for the four food groups were calculated in each region. Then $\chi^{2}$ tests for the association between region and frequency of food purchases were performed for 2005 and 2013 separately. The same procedure was followed to assess food sales in the three different retail concepts (supermarkets, low-price stores and convenience stores).

Calculations were carried out in Microsoft ${ }^{\circledR}$ Excel version 2010 using pivot tables. Statistical analyses were performed in the statistical software package IBM SPSS Statistics 21.

\section{Results}

\section{Food sales of NOVA food groups}

Figure 1 shows the share of food sales for the four food groups in 2005 and 2013 in terms of the frequency of purchase and expenditure. Sales of ultra-processed products were at a much higher level than sales of minimally processed foods, culinary ingredients and processed products for both indicators in both years. Approximately $58 \%$ of purchases and $48 \%$ of expenditure corresponded to ultra-processed foods. Minimally processed foods accounted for $17 \%$ of purchases and $33 \%$ of expenditure. The higher share of expenditure than purchases for minimally processed foods indicates that these foods had a relatively higher average price per purchase than did the three other food groups. Processed products accounted for $11 \%$ of purchases and $10 \%$ of expenditure. Culinary ingredients were purchased least frequently $(6 \%)$ and accounted for the smallest share of expenditure (3-4\%) in both years.

The unclassifiable food items (Table 2) totalled $8.4 \%$ of purchases in 2005 and 2013, 6.3\% of expenditure in 2005 and $5.9 \%$ in 2013. Table 2 shows how they contribute to underestimation of frequency and expenditure for the four NOVA groups by being excluded from the analysis.

\section{Food sales per subgroup}

Shares of purchases and expenditure for subgroups are shown in Figs 2 and 3, respectively. The subgroup that was most frequently purchased and held the largest expenditure share, both in 2005 and 2013, is sweets, snacks and desserts. These items were purchased more than twice as often as the second most purchased group (cakes, pastries and cookies in 2005 and breads in 2013) and equally as often as all minimally processed foods items combined.

Table 3 shows shares of food sales for all subgroups. If aggregating all purchases of sweet ultra-processed products, ${ }^{*}$ these accounted for every third purchase in 2013. Thus, for each purchase of a minimally processed food, two sweet ultra-processed products were purchased. In expenditure share, sweet ultra-processed products accounted for about 23\%, compared with $33 \%$ for all minimally processed foods, in 2013.

Results also show that Norwegians spent less and purchased less frequently minimally processed meat and poultry compared with processed and ultra-processed meat and poultry. The same was found for fish and potatoes (roots and tubers, compared with potato chips).

Table 4 lists the ten most sold subgroups and shows a predominance of food groups from ultra-processed products in both years and for both purchases and expenditure. Ultra-processed products accounted for the seven most frequently purchased items in 2005 and 2013. Of the ten subgroups on which Norwegians spent the most, five were ultra-processed products in 2005 and 2013.

\section{Evolution of food sales between 2005 and 2013}

Table 3 shows that share of purchase and expenditure on the four food groups changed minimally between 2005 and 2013 , but in favour of minimally processed foods and in disfavour of processed products. Share of food expenditure on culinary ingredients decreased. Ultra-processed products decreased their share of purchases, but accounted for a larger share of expenditure, meaning that average value of purchases increased. Pearson's $\chi^{2}$ test showed that time had a small, but significant effect on the frequency of purchase of food groups $\left(\chi^{2}(3)=203195, P<0 \cdot 001\right.$, Cramer's $V=0 \cdot 017$, $P<0.001)$. Significant standardized residuals are shown in Table 3. As indicated by the weak effect size measure, the absolute changes in share of frequency of purchases were small for all food groups.

Table 3 also shows relative changes between 2005 and 2013 for subgroups. There was a statistically significant association between purchases of subgroups and time $\left(\chi^{2}(30)=6699211, P<0 \cdot 001\right)$. The relationship was weak (Cramer's $V=0.096, P<0.001)$. Significant standardized residuals are shown in Table 3. Fish and seafood, squashes and juice, eggs, vegetable products, and processed meat and poultry were the only subgroups that did not have statistically significant standardized residuals in either year.

The changes in the subgroups within minimally processed foods show increased sales of fruits, vegetables, roots and tubers - these foods were both purchased more frequently and a larger share of expenditure was dedicated to them. Most remarkable was the increase for fruits and berries with a doubling of the share of purchases and a $50 \%$ increase in the share of expenditure. Fish and seafood were not purchased more frequently, but Norwegians spent more of their food budgets on fish and seafood. Meat and poultry were

\footnotetext{
* Sweet ultra-processed products = sweets, snacks and desserts; cakes, pastries and cookies; soft drinks; squashes and juice; and sweetened breakfast cereals.
} 


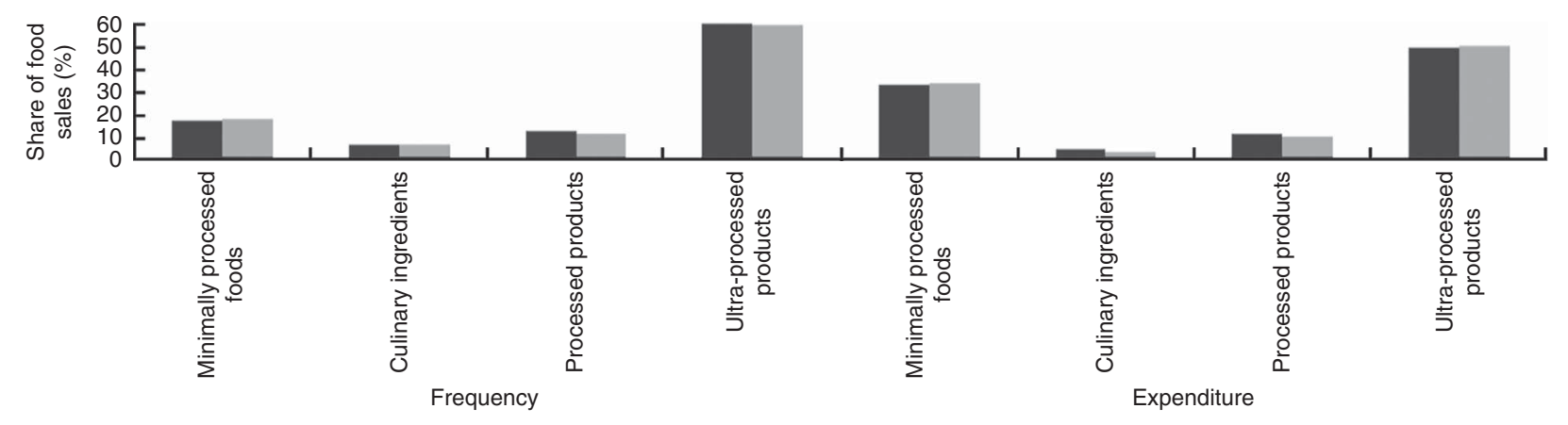

Fig. 1 Share of food sales in Norway in September $2005(\square)$ and September $2013(\square)$, in terms of frequency of purchase and expenditure, for four food groups classified according to their extent and purpose of industrial processing

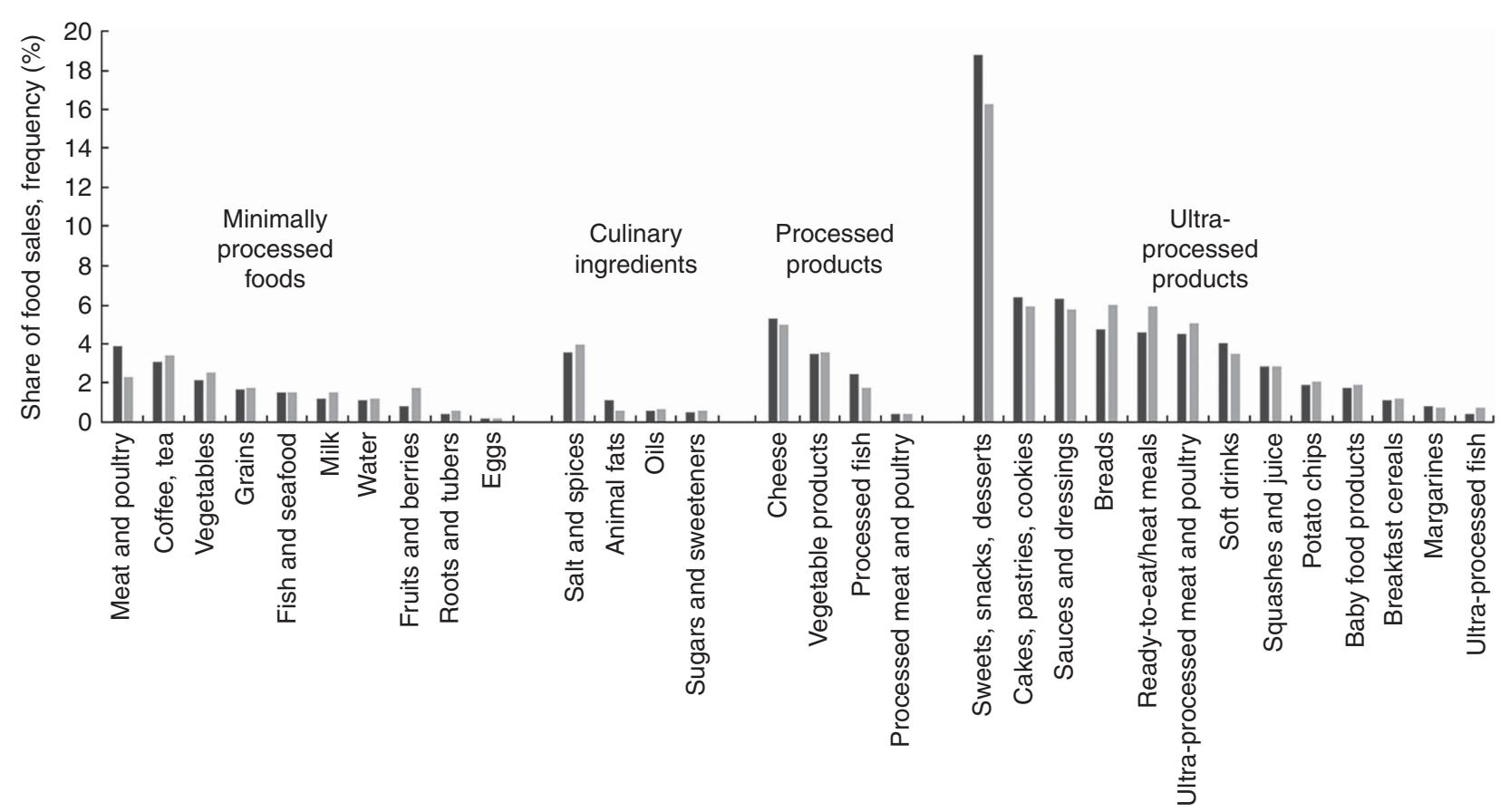

Fig. 2 Share of food sales in Norway in September $2005(\square)$ and September $2013(\square)$, in terms of frequency of purchase, for food subgroups within four food groups classified according to their extent and purpose of industrial processing

purchased less frequently and a smaller share of expenditure was dedicated to them.

Within ultra-processed products, results show increased purchases and expenditures on ready-to-eat/heat meals, breads, ultra-processed meat and poultry, and ultra-processed fish, which are all 'meal-type' products. Purchases and expenditures on chocolate, sweets, snacks, desserts, cakes and pastries, which are all sweet 'snack-type' products, decreased. Soft drinks were purchased less frequently, but a higher share of expenditure was dedicated to them.

\section{Comparison of retail concepts}

Retail concept had a statistically significant, but weak effect on the frequency of purchase of food groups in both $2005\left(\chi^{2}(6)=399739, \quad P<0.001\right.$, Cramer's $V=0.038$, $P<0.001)$ and $2013\left(\chi^{2}(6)=647255, P<0 \cdot 001\right.$, Cramer's $V=0.027, P<0 \cdot 001)$.
Figure 4 shows shares of purchases and expenditure on the four food groups in the three retail concepts. In general, a higher share of minimally processed foods and a lower share of ultra-processed products than in other concepts characterized food sales in supermarkets. Food sales in convenience stores were characterized by the opposite. In supermarkets, about $34 \%$ of expenditure was on minimally processed foods and $47 \%$ on ultra-processed products, compared with $27 \%$ and $54 \%$, respectively, in convenience stores. For culinary ingredients and processed products, share of expenditure was almost equal in 2013 across concepts. In 2013, convenience stores had the highest share of purchases of minimally processed foods.

Minimally processed foods and ultra-processed products increased their share of purchases and expenditure in all three concepts between 2005 and 2013, while 


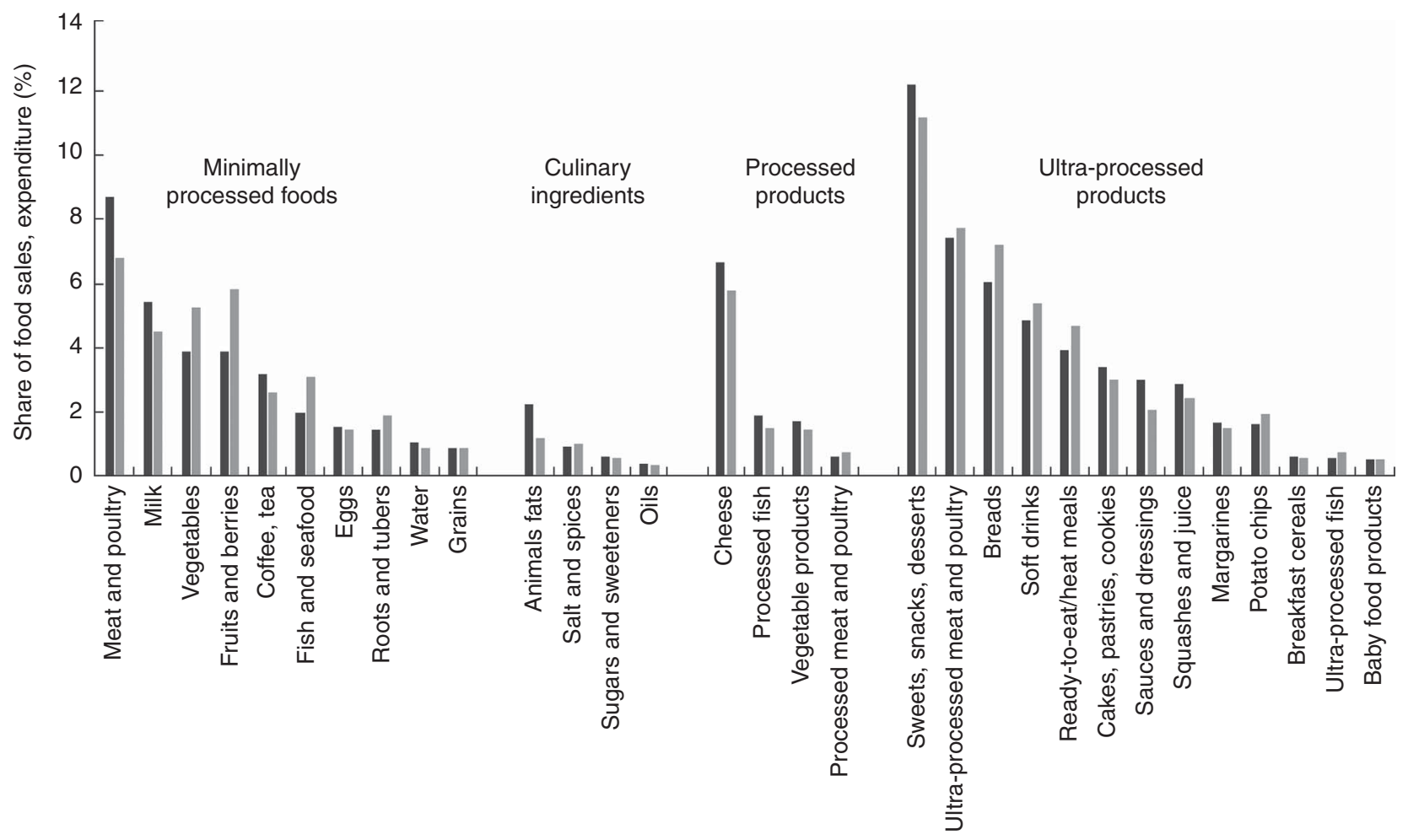

Fig. 3 Share of food sales in Norway in September $2005(\square)$ and September $2013(\square)$, in terms of expenditure, for food subgroups within four food groups classified according to their extent and purpose of industrial processing

Table 4 Ten most sold subgroups in Norway in September 2005 and September 2013, in terms of share of purchases (\%) and share of expenditure (\%)

\begin{tabular}{|c|c|c|c|c|c|c|c|}
\hline \multicolumn{4}{|c|}{2005} & \multicolumn{4}{|c|}{2013} \\
\hline Rank & Subgroup & Share $(\%)$ & Food group & Rank & Subgroup & Share (\%) & Food group \\
\hline \multicolumn{8}{|c|}{ Share of purchases } \\
\hline 1 & Sweets, snacks and desserts & $18 \cdot 7$ & UPP & 1 & Sweets, snacks and desserts & $16 \cdot 2$ & UPP \\
\hline 2 & Cakes, pastries and cookies & 6.4 & UPP & 2 & Breads & 6.0 & UPP \\
\hline 3 & Sauces and dressings & $6 \cdot 3$ & UPP & 3 & Cakes, pastries and cookies & $5 \cdot 9$ & UPP \\
\hline 4 & Cheese & $5 \cdot 3$ & PP & 4 & Ready-to-eat/heat meals & 5.9 & UPP \\
\hline 5 & Breads & 4.8 & UPP & 5 & Sauces and dressings & $5 \cdot 8$ & UPP \\
\hline 6 & Ready-to-eat/heat meals & 4.6 & UPP & 6 & Ultra-processed meat and poultry & $5 \cdot 0$ & UPP \\
\hline 7 & Ultra-processed meat and poultry & 4.5 & UPP & 7 & Cheese & $5 \cdot 0$ & PP \\
\hline 8 & Soft drinks & $4 \cdot 1$ & UPP & 8 & Salt and spices & 4.0 & $\mathrm{Cl}$ \\
\hline 9 & Meat and poultry & 3.9 & MPF & 9 & Vegetable products & 3.6 & PP \\
\hline 10 & Salt and spices & 3.6 & $\mathrm{Cl}$ & 10 & Soft drinks & 3.5 & UPP \\
\hline \multicolumn{8}{|c|}{ Share of expenditure } \\
\hline 1 & Sweets, snacks and desserts & $12 \cdot 2$ & UPP & 1 & Sweets, snacks and desserts & $11 \cdot 2$ & UPP \\
\hline 2 & Meat and poultry & $8 \cdot 7$ & MPF & 2 & Ultra-processed meat and poultry & $7 \cdot 7$ & UPP \\
\hline 3 & Ultra-processed meat and poultry & $7 \cdot 4$ & UPP & 3 & Breads & $7 \cdot 2$ & UPP \\
\hline 4 & Cheese & $6 \cdot 7$ & PP & 4 & Meat and poultry & $6 \cdot 8$ & MPF \\
\hline 5 & Breads & $6 \cdot 0$ & UPP & 5 & Fruits and berries & $5 \cdot 8$ & MPF \\
\hline 6 & Milk & 5.4 & MPF & 6 & Cheese & $5 \cdot 8$ & PP \\
\hline 7 & Soft drinks & $4 \cdot 8$ & UPP & 7 & Soft drinks & $5 \cdot 4$ & UPP \\
\hline 8 & Ready-to-eat/heat meals & 3.9 & UPP & 8 & Vegetables & $5 \cdot 2$ & MPF \\
\hline 9 & Vegetables & 3.9 & MPF & 9 & Ready-to-eat/heat meals & 4.7 & UPP \\
\hline 10 & Fruits and berries & 3.9 & MPF & 10 & Milk & 4.5 & MPF \\
\hline
\end{tabular}

UPP, ultra-processed products; PP, processed products; MPF, minimally processed foods; $\mathrm{Cl}$, culinary ingredients.

culinary ingredients and processed products decreased their share for both indicators.

The subgroups also sold at different patterns in the three retail concepts. In supermarkets, sales of fish and seafood (purchase and expenditure), meat and poultry (expenditure), vegetables (expenditure), cheese (purchase and expenditure) and sauces and dressings (purchases) were higher than in the two others. Increase in expenditure on 


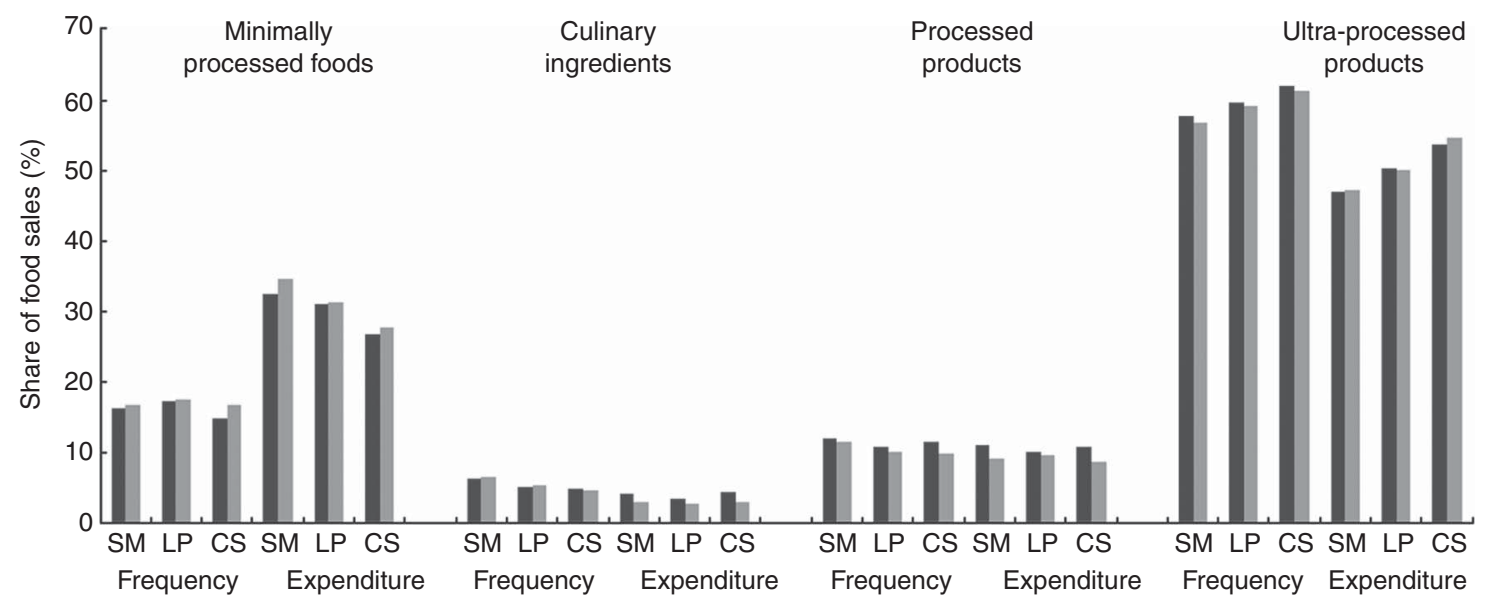

Fig. 4 Share of food sales in Norway in September $2005(\square)$ and September $2013(\square)$, in terms of frequency of purchase and expenditure, for four food groups classified according to their extent and purpose of industrial processing in three retail concepts (SM, supermarket, LP, low-price store, CS, convenience store)

fish between 2005 and 2013 took place in supermarkets only. The higher sales (purchase and expenditure) of ultra-processed products in convenience stores were mainly cakes, pastries and cookies, sweets, snacks and desserts, and soft drinks. The higher purchase of minimally processed foods in convenience stores in 2013 was due to fruits and berries, vegetables and water.

\section{Comparison of six geographic regions}

Region of sale had a weak, but significant effect on purchases of food groups in both $2005\left(\chi^{2}(15)=182790\right.$, $P<0.001, \quad$ Cramer's $V=0.015, \quad P<0.001)$ and 2013 $\left(\chi^{2}(15)=112\right.$ 406, $P<0.001$, Cramer's $\left.V=0.016, P<0 \cdot 001\right)$. No particular patterns were detected, as no regions were consistently higher or lower in purchases of any food groups. However, for expenditure, all regions seemed to convert to similar levels, except in Oslo, where expenditure increased to be higher than in other regions for minimally processed foods and decreased to be lower than in other regions for ultra-processed products (Fig. 5).

\section{Discussion}

The present study found that in 2005 and 2013, ultraprocessed products accounted for the largest part of food purchase and expenditure in Norway, indicating a high consumption of such items, and that these have replaced homemade meals made from minimally processed foods and culinary ingredients. Sweet ultra-processed products accounted for three out of ten purchased food items and more than a fifth of expenditure on food, but results indicated that sales of these decreased between 2005 and 2013. The study found increased sales for fruits and berries, vegetables, roots and tubers, ready-to-eat/heat meals, breads, and meat and poultry products, and that there was a large increase in share of expenditure on minimally processed foods in Oslo.
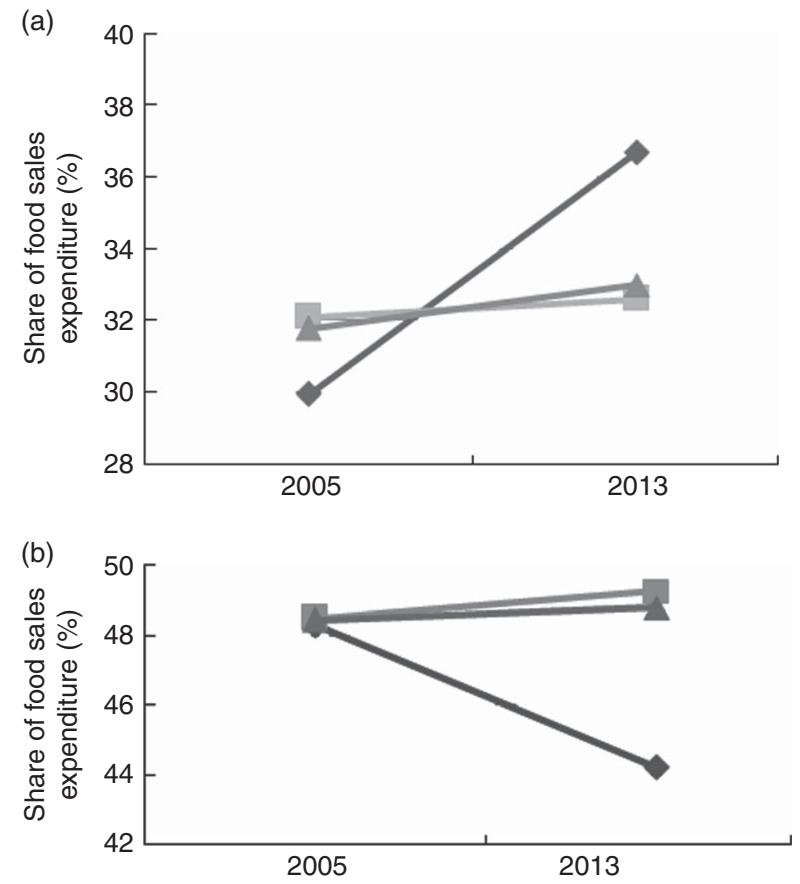

Fig. 5 Evolution of food expenditure in geographic regions of Norway $(\cdots$, Oslo; $\ldots$, Norway excluding Oslo; $\ldots$, Norway overall) in September 2005 and September 2013 for two food groups classified according to their extent and purpose of industrial processing: (a) minimally processed foods; and (b) ultra-processed products

\section{Limitations and strengths}

While providing insights on food consumption and having been used elsewhere ${ }^{(17)}$, the use of food sales data as proxies for food consumption has several limitations.

First, there are elements of inaccuracy related to the indicators used. Frequency of purchase has two main weaknesses. Volume of food (grams and kilojoules) will differ between each purchase and foods might be purchased at different frequencies according to the possibility of storage 
and bulk purchasing. Food items that are purchased seldom but in larger volumes are therefore underestimated with this indicator. To minimize this limitation, the expenditure share for the food groups was included as a second indicator, which adds more weight to larger and more expensive purchases. The expenditure indicator also has limitations, as there is no standardization of volume of food per price. Changes between years might not represent actual changes in volumes purchased, but could represent price changes. The results should be interpreted with caution in the light of these limitations.

Second, food waste is not accounted for in retail data. Studies show that significant amounts of foods are wasted; for example, $30 \%$ in the $\mathrm{UK}^{(34)}$. Minimally processed foods are likely to be wasted more often, as these are more perishable. This bias may have led to overestimation of the consumption of minimally processed foods.

Finally, retail data do not include all sources of food consumption, such as foods eaten at restaurants. Pizza restaurants, gas stations and shopping mall cafeterias are those most frequently visited in Norway ${ }^{(35)}$, suggesting that consumption of ultra-processed products could be underestimated in our study.

Data were collected during September in 2005 and 2013, and uncertainty exists on whether retail in September is representative for whole-year retail. Measures have been taken to reduce this uncertainty; September was chosen as there are no official vacations or holidays during this month. Additionally, retail data are measured at population level and results cannot be extrapolated to individuals or households.

Several strengths can also be identified in the study. For example, these data are not prone to responder or information bias, as they are collected electronically and from all individuals purchasing food in the data collection period. Further, the foods and culinary ingredients purchased for home preparation of meals are identified and separated from the items purchased processed or ultraprocessed products, which reduces risk of misclassification and thus measurement bias. Finally, the barcode scanner data are comprehensive, covering close to all food items available from food retailers, and are collected consistently over time. Using these data allows for a more representative sample than traditional food consumption studies.

\section{Comparison}

A positive correlation between gross domestic product per capita and consumption rates of ultra-processed products has been found ${ }^{(8)}$. A comparison of results of the present study with those from other high-income countries is therefore most relevant. Euromonitor sales data on packaged foods, snacks and soft drinks (proxy for ultra-processed foods) have been analysed in seventy-nine high- and middle-income countries, showing that ultra-processed products dominate the food supplies of high-income countries ${ }^{(8)}$. Studies from Canada show that shares of household food expenditure and dietary energy availability fell for minimally processed foods and culinary ingredients, and rose for ready-to-consume products, between 1938 and $2011^{(2,10)}$. The expenditure share for minimally processed foods, culinary ingredients and readyto-consume products in 2011 was $40.8 \%, 4.8 \%$ and $54.4 \%$, respectively. Corresponding shares for energy intake were $25.6 \%, 12.7 \%$ and $61.7 \%{ }^{(2)}$. Similarly, in the UK, share of energy intake was $22.9 \%, 13.7 \%$ and $63.4 \%$ for minimally processed foods, culinary ingredients and ready-to-consume products, respectively ${ }^{(36)}$. The ready-to-consume group consisted mainly of ultra-processed products in all the abovementioned studies. Euromonitor sales data show that among Western European countries, Norway had the third highest annual per capita sales of ultra-processed products in $2012^{(37)}$. Although results are not directly comparable as different methods and indicators of food consumption have been applied, they indicate that food consumption in Norway in terms of the new classification is similar to other high-income countries and dominated by ultra-processed products.

The present study found that the share of purchases and expenditure on ultra-processed products increased minimally between 2005 and 2013. It has been suggested that a market saturation point is reached for ultraprocessed products when these supply about $60 \%$ of energy and that this point has been reached in highincome countries ${ }^{(7,8,38,39)}$. Euromonitor data from 1998 to 2012 show that in high-income countries, including Norway, sales of soft drinks increased in the first half of the period, and then decreased, while sales of snacks were static ${ }^{(9)}$. The same study predicted growth of all ultraprocessed products in countries with very high per capita income (gross national income $\geq \$$ US 50000 ) to be close to zero. Another study on sales of packaged foods, snacks and soft drinks in seventy-nine high- and middle-income countries for the years 1997-2010 found that little or no growth in sales is expected in high-income countries by $2016^{(8)}$. In Western Europe, total volume sales growth of ultra-processed food and drinks started declining in $2012^{(37)}$.

Our findings are in line with other studies of Norwegian dietary development, although comparisons of results is challenging as other studies do not separate foods groups in accordance with the new framework. A 2012 report from the Norwegian Directorate of Health indicated that expenditure share for sugary foods and beverages accounted for almost one-fifth of all expenses for food and non-alcoholic beverages ${ }^{(40)}$, which is similar to the share found in the present study (23\%). High intakes of free sugars, sweets and soft drinks is a well-known issue in Norway and is previously documented in several surveys ${ }^{(40,41)}$. The way sugar is consumed has changed, through decreasing use of table sugars, syrups, etc. for home use and increasing consumption of sugars through candy and soft drinks. Sweet ultra-processed products, especially candy, chocolate and sweetened 
beverages, are the largest contributors to intake of added sugars for children, adolescents and adults ${ }^{(40,42)}$. The findings in the current study highlight sweet ultra-processed products as the main vector for sugar intake.

The change in use of sugars illustrates another aspect of changing dietary patterns. Culinary ingredients are indicators of homemade meals and dishes, as they are not used alone, but rather as ingredients in the preparation of meals and dishes from minimally processed foods ${ }^{(3,10)}$. The low share of culinary ingredients sold in Norway indicates that ultra-processed products have replaced homemade meals and dishes. A previous study found that although homemade meals are highly valued in Norway, processed and ultra-processed products are often used in meal preparations on a daily basis ${ }^{(43)}$.

Annual reports on dietary development show increasing consumption of vegetables and fruits between 1999 and $2011^{(40,41)}$. In the present study, an increase in sales of fruit, berries and vegetables was found between 2005 and 2013. Consumption of potato, a staple food in the Norwegian diet, has more than halved since the 1970s, while consumption of potato products has multiplied many times. Half of potato crops are now used for processed potato products ${ }^{(41)}$. The present study found similar issues: minimally processed potatoes accounted for less than $0.5 \%$ of purchases and about $1.5 \%$ of food expenditures, while potato chips accounted for $2 \%$ of purchases and $1 \cdot 5-2 \%$ of food expenditures.

Meat consumption is reported to be increasing in Norway ${ }^{(41)}$. Monteiro et $a l .{ }^{(3)}$ observed that it is often assumed that consumption of all meat is increasing, while in Brazil the only meat whose consumption is increasing is processed meat. The present study indicates the same might be true in Norway.

\section{Implications for bealth}

Our study did not address nutrient contents of food consumption nor health outcomes, and health implications of our findings are thus difficult to assess. However, results from Canada may provide preliminary indications for Norway. One study showed that only the quintile of the population with lowest consumption of ultraprocessed products was anywhere near fulfilling nutrient recommendations from the $\mathrm{WHO}^{(10)}$. The other $80 \%$ of the population consumed more than half of energy intake through ultra-processed products and would need to reduce the energy share of these in the diet to meet the WHO nutrient intake recommendations. If the nutrient profile of such diets in Norway is similar to that in Canada, a reduction of purchases and consumption of ultra-processed products is necessary for the prevention of obesity and NCD.

The high consumption of sweet ultra-processed products is an issue of special concern for health. Energy share from sugar exceeds the recommended $10 \%$, and children and adolescents consume an even higher energy share from sweets than adults ${ }^{(40,42)}$. There is evidence of the link between excessive intake of free sugars, especially through sugar-sweetened beverages, and overweight and $\mathrm{NCD}^{(44-46)}$. Although the high sugar intake is well known and problematic, the current study indicates that even more effort is needed on reducing intake of the sweet ultra-processed products that are the main vehicles for sugar intake.

The present study found increasing purchase and expenditure shares for fruits, berries, vegetables, roots and tubers, and fish and seafood within the minimally processed food group and decreasing purchase and expenditure shares for sweet ultra-processed products. These are dietary shifts in line with Norwegian dietary recommendations ${ }^{(47)}$. In Oslo, there was a significant shift in food sales towards a less processed consumption pattern. Market saturation for ultra-processed foods has been explained by increasing awareness of health outcomes in the population ${ }^{(39)}$. This development is predicted by nutrition transition theory and the present findings may therefore be indications of Norwegian dietary patterns going into the fifth stage of the nutrition transition, as postulated by Popkin ${ }^{(48)}$.

Our findings might be related to the increasing health awareness and focus on healthy diets that have been observed in Norway over the past years ${ }^{(49,50)}$. According to Euromonitor, health and wellness is the most prominent trend in Norway affecting demand for food and drink consumption $^{(51)}$. Consumers are to a higher degree sceptic of the food selection in fast-food outlets due to health concerns and prefer improved selection of fruits, vegetables and foods with less fat and more fibre ${ }^{(52)}$. There is also attention to the health benefits of traditional foods and diets through the New Nordic Diet ${ }^{(53)}$.

A main characteristic of the increasing health awareness in Norway is attention to eating homemade meals based on 'natural' ingredients ${ }^{(49,50)}$, which can be related to our results regarding minimally processed foods. A recent study from Norway ${ }^{(50)}$ found that the most important criteria for judging a food as healthy are being non-processed and 'made from scratch'. Further, foods associated with mass production and the globalized food system have low status among Norwegian consumers. Between 2005 and 2013, the share of Norwegians agreeing that processed foods can be as healthy as other foods decreased from $51 \%$ to $39 \%{ }^{(50)}$. The foods most Norwegians are trying to avoid are sugar-sweetened beverages (78\%) and ready-made products $(74 \%)^{(54)}$.

However, the overall level of purchases of and expenditure on ultra-processed products did not decrease, and for some, especially ready-to-eat/heat meals and processed meat and poultry, both purchases and expenditure increased. Further, limitations of the proxies used urge caution in interpreting observed changes as actual changes in consumption. 


\section{Policy implications}

The present study indicates that Norwegian diets are composed predominantly of ultra-processed products, which is likely to be contributing to the rising rates of overweight, obesity and diet-related NCD in the country. Along with other studies, it indicates an alarmingly high consumption of ultra-processed food products high in sugar, salt, and saturated and trans-fats.

Norwegian efforts to improve diets are outlined in a recent White Paper on public health ${ }^{(20)}$, which calls for multisectoral action for improved health and nutrition. Strategies under implementation include:

1. information campaigns and promotion of dietary guidelines, which encourage consumption of fruits and vegetables, fish and whole-grain products, and limit consumption of sugar, red and processed meats, and products high in saturated fats and salt;

2. collaboration with the food industry in product reformulation, especially for reducing contents of salt, trans-fatty acids and palm oil;

3. a voluntary labelling scheme, 'The Keyhole', which indicates healthier choices within a food group based on criteria for contents of added sugar, salt and saturated fats; and

4. a voluntary self-regulation scheme on the marketing of unhealthy food products to children.

While these efforts are important, the evidence base for the effect of informational campaigns and voluntary efforts by the food industry is weak ${ }^{(38,55)}$. Although product reformulation and labelling are important strategies to help consumers make healthier choices, they may not reduce overall consumption of ultra-processed products. Additionally, it has been indicated $^{(38,55,56)}$ that there is a conflict between public health interests (reducing intake of ultra-processed products) and corporate interests (increasing sales of ultra-processed products). Efficient measures to reduce the consumption of sugar (especially sweet ultra-processed products), salt and fats will need to address such issues. Dietary guidelines that make recommendations on choice of foods and meals based on the food groups in the NOVA classification (as in Brazil) could be more suitable in the current context of eating to promote health and well-being ${ }^{(19)}$, although further research for Norway would be needed for their development.

\section{Research gaps and potential for future research}

To further assess and confirm the findings from Norway, studies on the energy contribution of food groups in the new classification to the Norwegian diet are needed, as well as studies linking the consumption of specific groups to health outcomes. Research from Brazil ${ }^{(3)}$ and Canada ${ }^{(10)}$ indicates that socio-economic differences in intake of ultra-processed foods are present in low- and middle- income countries, but not in high-income countries. However, studies from Norway show socio-economic differences in food consumption (using 'conventional' food classifications) ${ }^{(42)}$ and in health ${ }^{(20)}$.
Studies investigating socio-economic differences in intake of ultra-processed foods would therefore be of particular interest.

\section{Conclusion}

The present study indicates that Norwegian diets are composed predominantly of ultra-processed products, which account for $60 \%$ of purchases and $50 \%$ of food expenditure. Sweet ultra-processed products alone account for every third food purchase and a fifth of food expenditure. Drawing on findings from other countries, such diets are likely to be contributing to the rising rates of overweight, obesity and related NCD. Based on evidence from the present and previous studies, it is recommended to decrease the consumption of ultra-processed products and increase the consumption of meals prepared from minimally processed foods and culinary ingredients. This should be promoted through concerted policy efforts involving all sectors.

\section{Acknowledgements}

Financial support: This study received financial support from the Oslo and Akershus University College of Applied Sciences for purchase of the database from Statistics Norway. The funder had no role in the design, analysis or writing of this article. Conflict of interest: None. Authorship: The empirical design was planned by S.L.S. and S.I.G. Data analysis was conducted by S.L.S. and supervised by S.I.G. The initial draft was written by S.L.S. with substantial inputs from S.I.G. S.L.S., S.I.G. and L.T. developed successive drafts. Each author has seen and approved the content of the submitted manuscript. Ethics of human subject participation: Not applicable.

\section{References}

1. Monteiro CA (2009) Nutrition and health. The issue is not food, nor nutrients, so much as processing. Public Health Nutr 12, 729-731.

2. Moubarac JC, Batal M, Martins AP et al. (2014) Processed and ultra-processed food products: consumption trends in Canada from 1938 to 2011. Can J Diet Pract Res 75, 15-21.

3. Monteiro CA, Levy RB, Claro RM et al. (2011) Increasing consumption of ultra-processed foods and likely impact on human health: evidence from Brazil. Public Health Nutr 14, 5-13.

4. Martins AP, Levy RB, Claro RM et al. (2013) Increased contribution of ultra-processed food products in the Brazilian diet (1987-2009). Rev Saude Publica 47, 656-665.

5. Crovetto M \& Uauy R (2012) Changes in processed food expenditure in the population of Metropolitan Santiago in the last twenty years. Rev Med Chil 140, 305-312.

6. Juul F \& Hemmingsson E (2015) Trends in consumption of ultra-processed foods and obesity in Sweden between 1960 and 2010. Public Health Nutr 18, 3096-4107.

7. Monteiro CA \& Cannon G (2012) The impact of transnational 'big food' companies on the South: a view from Brazil. PLoS Med 9, e1001252.

8. Stuckler D, McKee M, Ebrahim S et al. (2012) Manufacturing epidemics: the role of global producers in increased consumption of unhealthy commodities including processed foods, alcohol, and tobacco. PLoS Med 9, e1001235. 
9. Monteiro CA, Moubarac JC, Cannon G et al. (2013) Ultraprocessed products are becoming dominant in the global food system. Obes Rev 14, 21-28.

10. Moubarac JC, Martins AP, Claro R et al. (2013) Consumption of ultra-processed foods and likely impact on human health. Evidence from Canada. Public Health Nutr 16, 2240-2248.

11. Crovetto MM, Uauy R, Martins AP et al. (2014) Household availability of ready-to-consume food and drink products in Chile: impact on nutritional quality of the diet. Rev Med Chil 142, 850-858.

12. Louzada ML, Bortoletto Martins AP, Silva Canella D et al. (2015) Ultra-processed foods and the nutritional dietary profile in Brazil. Rev Saude Publica 49, 38.

13. Canella DS, Levy RB, Martins APB et al. (2014) Ultra-processed food products and obesity in Brazilian households (2008-2009). PLoS One 9, e92752.

14. Louzada ML, Baraldi LG, Steele EM et al. (2015) Consumption of ultra-processed foods and obesity in Brazilian adolescents and adults. Prev Med 81, 9-15.

15. Tavares LF, Fonseca SC, Garcia Rosa ML et al. (2012) Relationship between ultra-processed foods and metabolic syndrome in adolescents from a Brazilian Family Doctor Program. Public Health Nutr 15, 82-87.

16. Swinburn B, Caterson I, Seidell JC et al. (2004) Diet, nutrition and the prevention of excess weight gain and obesity. Public Health Nutr 7, 123-146.

17. Baker P \& Friel S (2014) Processed foods and the nutrition transition: evidence from Asia. Obes Rev 15, 564-577.

18. Monteiro CA, Gomes FS \& Cannon G (2010) The snack attack. Am J Public Health 100, 975-981.

19. Monteiro CA, Cannon G, Moubarac JC et al. (2015) Dietary guidelines to nourish humanity and the planet in the twenty-first century. A blueprint from Brazil. Public Health Nutr 18, 2311-2322.

20. Ministry of Health and Care Services (2013) Folkehelsemeldingen: God helse - felles ansvar. Meld. St. 34 (2012-2013) (White Paper). Oslo: Regjeringen.

21. Meyer HE \& Tverdal A (2005) Development of body weight in the Norwegian population. Prostaglandins Leukot Essent Fatty Acids 73, 3-7.

22. Folkehelseinstituttet (2014) Folkehelserapporten 2014: Helsetilstanden $i$ Norge. Rapport 2014:4. Oslo: Nasjonalt folkehelseinstitutt.

23. Ministry of Health and Care Services (2003) Resept for et sunnere Norge: Folkehelsepolitikken. St.meld. $n r .16$ (2002-2003) (White Paper). Oslo: Regjeringen.

24. Helsedirektoratet (2015) Utviklingen $i$ norsk kosthold 2014. Oslo: Helsedirektoratet.

25. Rodrigues J \& Haraldsen F (2005) Den nye matvareindeksen: bruk av strekkodedata i konsumprisindeksen. Økonomiske Analyser 2005, issue 4, 42-49.

26. Henriksen K (2006) Utvalgsplan til konsumprisindeksens nye matvareindeks: basert på strekkodedata. In Notater, vol. 2006/47. Oslo: Statistisk sentralbyrå.

27. Johansen Ic \& Nygaard R (2010) Skjevheter i prisindeksen for matvarer og alkoholfrie drikkevarer? In Notater, vol. 2010/30. Oslo: Statistisk sentralbyrå.

28. Johansen I (2012) Bruk av strekkodedata i matvareindeksen. Økonomiske Analyser 2012, issue 6, 51-56.

29. United Nations Statistics Division (2015) Detailed structure and explanatory notes COICOP (Classification of Individual Consumption According to Purpose). http://unstats.un.org/ unsd/cr/registry/regcst.asp?Cl=5 (accessed April 2015).

30. Monteiro CA, Levy RB, Claro RM et al. (2010) A new classification of foods based on the extent and purpose of food processing. Cad Saude Publica 26, 2039-2049.

31. Monteiro CA, Cannon G, Levy RB et al. (2012) The food system. Ultra-processing. The big issue for nutrition, disease, health, well-being (Commentary). World Nutr 3, $527-569$.
32. Food and Agriculture Organization of the United Nations (2015) Guidelines on the Collection of Information on Food Processing Through Food Consumption Surveys. Rome: FAO.

33. Opplysningskontoret for Meieriprodukter (2015) Meieristatistikk. http://www.melk.no/melk-og-meierifakta/ meieristatistikk/ (accessed April 2015).

34. Ventour L (2008) The Food We Waste. Banbury: WRAP.

35. Bugge A \& Lavik R (2007) A spise ute - bvem, hva, bvor, bvordan, bvorfor og når. Oslo: SIFO.

36. Moubarac JC, Claro RM, Baraldi LG et al. (2013) International differences in cost and consumption of ready-toconsume food and drink products: United Kingdom and Brazil, 2008-2009. Glob Public Health 8, 845-856.

37. Pan American Health Organization \& World Health Organization (2015) Ultra-Processed Food and Drink Products in Latin America: Trends, Impact on Obesity, Policy Implications. Washington, DC: PAHO/WHO.

38. Moodie R, Stuckler D, Monteiro CA et al. (2013) Profits and pandemics: prevention of harmful effects of tobacco, alcohol, and ultra-processed food and drink industries. Lancet 381, 670-679.

39. Kleiman S, Ng SW \& Popkin B (2012) Drinking to our health: can beverage companies cut calories while maintaining profits? Obes Rev 13, 258-274.

40. Helsedirektoratet (2012) Utviklingen $i$ norsk kosthold 2012. Oslo: Helsedirektoratet.

41. Helsedirektoratet (2013) Utviklingen i norsk kosthold. Matforsyningsstatistikk. Oslo: Helsedirektoratet.

42. Andersen LF \& Øverby NC (2002) Ungkost-2000: landsomfattende kostholdsundersøkelse blant elever $i$ 4. - og 8 . klasse i Norge. Oslo: Sosial- og helsedirektoratet.

43. Bugge AB (2006) Middag: en sosiologisk analyse av den norske middagspraksis. Trondheim: Tapir Akademiske Forlag.

44. Ambrosini GL, Oddy WH, Rae Chi H et al. (2013) Prospective associations between sugar-sweetened beverage intakes and cardiometabolic risk factors in adolescents. Am J Clin Nutr 98, 327-334.

45. Malik VS, An P, Willett WC et al. (2013) Sugar-sweetened beverages and weight gain in children and adults: a systematic review and meta-analysis. Am J Clin Nutr 98, 1084-1102.

46. World Health Organization (2003) Diet, Nutrition and the Prevention of Chronic Diseases. Joint WHO/FAO Expert Consultation. WHO Technical Report Series no. 916. Geneva: WHO.

47. Helsedirektoratet (2014) Anbefalinger om kosthold, ernaering og fysisk aktivitet. Oslo: Helsedirektoratet.

48. Popkin BM (1993) Nutritional patterns and transitions. Popul Dev Rev 19, 138-157.

49. Bugge A (2012) Spis deg sunn, sterk, slank, skjønn, smart, sexy...: finnes det en diett for alt? Oslo: SIFO.

50. Bugge AB (2015) Mat, måltid og moral - bvordan spise rett og riktig. Fagrapport nr 3 - 2015. Oslo: SIFO.

51. Euromonitor (2015) Health and Wellness in Norway. http:// www.euromonitor.com/health-and-wellness-in-norway/ report (accessed October 2015).

52. Bugge A, Lillebø K \& Lavik R (2009) Food on the Run Possibilities and Barriers/Limitations for New And Healthier Eating Concepts in the Fast Food Market. Oslo: SIFO

53. Mithril C, Dragsted LO, Meyer C et al. (2012) Guidelines for the New Nordic Diet. Public Health Nutr 15, 1941-1947.

54. Bugge AB (2015) Hva kjennetegner forbrukernes preferanser, prioriteringer og praksiser knyttet til fisk og grønnsaker. In HealthMeal Hvordan nà de ernoeringsmessige målsetningene om økt forbruk av fisk og grønnsaker?, pp. 13-28 [AB Bugge, editor]. Oslo: SIFO.

55. Stuckler D \& Nestle M (2012) Big food, food systems, and global health. PLoS Med $\mathbf{9}$, e1001242.

56. Gomes FS \& Lobstein T (2011) Food and beverage transnational corporations and nutrition policy. SCN News 39, $57-65$. 